Conclusions: In our series, biological therapy, especially IFX and ADA, is effective and relatively safe in patients with PUK refractory to standard systemic treatment.

Disclosure of Interest: None declared

DOI: 10.1136/annrheumdis-2017-eular.3576

\section{AB0338 HEADS-UP! SARCOIDOSIS AND RHEUMATOID ARTHRITIS CO-EXIST}

\section{Zickuhr, R. Hajj-Ali. Rheumatology, Cleveland Clinic Foundation, Cleveland,} United States

Background: Sarcoidosis and rheumatoid arthritis (RA) uncommonly co-occur. How dual diagnosis affects these patients' clinical phenotype is unknown. Objectives: To characterize the clinical and laboratory phenotype and to increase awareness of the coexistence of sarcoidosis and RA.

Methods: We searched PubMed from 1980-2016 for relevant articles using key words "sarcoidosis" and "rheumatoid arthritis," excluding cases with tumor necrosis factor inhibitors. We found 12 cases, omitted 5 lacking clinical detail, and added 2 from our experience at the Cleveland Clinic. Clinical features, laboratory and imaging findings were reviewed and summarized.

Results: Females comprised $7 / 9$ cases $(77 \%)$. Our cases are the first to describe men with dual diagnosis. Of the 8 cases reporting ethnicity, $4(50 \%)$ were white. The mean age at time of diagnosis was 35.3 years for RA and 51.0 years for sarcoidosis. In $5 / 9$ cases (55\%), RA preceded sarcoidosis. RA affected the hands in $8 / 9$ patients $(88.9 \%)$. Of the 8 cases reporting symptoms of sarcoidosis, 5 $(62.5 \%)$ had dyspnea. All cases $(100 \%)$ had elevated rheumatoid factor (RF) and, when checked, anti-citrullinated peptide (anti-CCP) antibodies. Angiotensin converting enzyme (ACE) was elevated in $6 / 9$ patients $(66.6 \%)$. Of the 5 patients with joint imaging, $4(80 \%)$ had inflammatory changes. All sarcoidosis $(100 \%)$ was biopsy-proven. One case $(11.1 \%)$ demonstrated concomitant pulmonary RA and sarcoidosis.

Conclusions: Sarcoidosis and RA coexist in seropositive patients, most commonly in women in their fourth through sixth decades of life. RA preceded sarcoidosis about half the time. Hand arthritis and dyspnea were the most common symptoms for RA and sarcoidosis, respectively. Awareness of this dual diagnosis may help identify RA and sarcoidosis earlier and prevent treatment delay.

References:

[1] Enzenauer RJ and West SG. Sarcoidosis in autoimmune disease. Arth \& Rheum, 1992; 22(1):1-17.

[2] Menard O, et al. Association of histologically proven rheumatoid arthritis with pulmonary sarcoidosis. Eur Respir J, 1995; 8;472-3.

[3] Kobak S, et al. Co-occurrence of rheumatoid arthritis and sarcoidosis. BMJ Case Rep, 2015;1-3.

[4] Kucera, MRF. A possible association of rheumatoid arthritis and sarcoidosis. Chest, 1989; 95:604-06.

[5] Leo G, et al. Simultaneous pulmonary involvement, histologically proven, of sarcoidosis and rheumatoid arthritis. Clin Exp Rheumatol, 2009;27(1):164

[6] Takashita M, et al. Mutilating rheumatoid arthritis associated with sarcoidosis: A case report. Clin rheum, 1995;14(5):576-9.

Disclosure of Interest: None declared

DOI: 10.1136/annrheumdis-2017-eular.5401

\section{AB0339 COMORBIDITIES AND RISK FACTORS OF CARDIOVASCULAR DISEASES IN RHEUMATOID ARTHRITIS PATIENTS}

L.V. Khimion ${ }^{1}$, I.V. Klymas ${ }^{1}$, I.M. Naishtetik ${ }^{2} .{ }^{1}$ Department of Family Medicine, Shupyk National Medical Academy of Postgraduate Education; ${ }^{2}$ Kyiv Regional Clinical Hospital, Kyiv, Ukraine

Background: It is well known, that atherosclerosis associated cardiovascular diseases in many cases determine the life expectancy in RA patients. At the same time, risk factors which promote the development of premature atherosclerosis, including comorbidities, remain uncertain.

Objectives: to analyze comorbid conditions in RA patients under age of 50 years and assess their impact on the vascular wall (evaluated by ultrasound investigation of the carotid arteries).

Methods: The study was conducted at the Department of Family Medicine, Shupyk NMAPE at the Kyiv Regional Clinical Hospital. The study included 126 RA patients, aged from 18 to 49 years (women - $102(81 \%)$, men - $24(19 \%)$, average age $43.82 \pm 8.8$ years, who provided written consent to participate in research. As a control group 30 persons without any autoimmune diseases (women - 25 (83.3\%) men - $5(16.7 \%)$, average age $42.4 \pm 8.6$ years) were examined. All RA patients and control group underwent comprehensive clinical, laboratory and instrumental examination to identify comorbid conditions including evaluation of atherogenesis by use of ultrasound examination of the carotid arteries with intima-media thickness (IMT) measurement and atherosclerosis plagues (AP) assessment.

Results: The frequency of identified comorbid conditions and diseases in RA patients and control group are presented in Table 1.

The average number of comorbid diseases/conditions per RA patient significantly exceeded its number in controls (4.13 and 1.67 respectively, $p<0.05$ ); most fre-
Table 1. The frequency of comorbidities in RA patients and control group

\begin{tabular}{|c|c|c|c|c|}
\hline \multirow[t]{2}{*}{ Diseases and conditions } & \multicolumn{2}{|c|}{$R A(n=126)$} & \multicolumn{2}{|c|}{ Control $(n=30)$} \\
\hline & $\mathrm{n}$ & $\%$ & $n$ & $\%$ \\
\hline Coronary heart disease & 12 & $9.52^{*}$ & 0 & 0 \\
\hline Arterial hypertension & 47 & $37.30^{\star}$ & 0 & 0 \\
\hline Neurocirculatory asthenia & 2 & $1.58^{\star}$ & 1 & 3.3 \\
\hline Dyslipidemia & 76 & $60.32^{*}$ & 2 & 6.67 \\
\hline Peptic ulcer & 6 & $4.76^{\star}$ & 1 & 3.30 \\
\hline Chronic gastritis & 29 & 23.00 & 3 & 10.0 \\
\hline Chronic pancreatitis & 19 & 15.08 & 5 & 16.67 \\
\hline Nonalcohol fatty liver disease & 77 & $61.11^{*}$ & 2 & 6.67 \\
\hline Cholesterosis of the gallbladder & 38 & $30.16^{*}$ & 1 & 3.33 \\
\hline Chronic cholecystitis & 46 & $36.51^{*}$ & 3 & 10.00 \\
\hline Gall stones & 8 & $8.25^{\star}$ & 0 & 0 \\
\hline Diabetes mellitus type 2 & 3 & $2.38^{\star}$ & 0 & 0 \\
\hline Diffuse goiter & 5 & $3.97^{\star}$ & 0 & 0 \\
\hline Autoimmune thyroiditis & 35 & $27.77^{\star}$ & 1 & 3.33 \\
\hline Chronic obstructive pulmonary disease & 5 & 3.97 & 4 & 13.33 \\
\hline Osteoarthritis of the spine & 42 & 33.33 & 9 & 30.00 \\
\hline Chronic kidney disease & 5 & 3.97 & 1 & 3.33 \\
\hline Abdominal obesity & 21 & 16.67 & 4 & 13.33 \\
\hline
\end{tabular}

${ }^{\star}$ The difference between groups is significant, $\mathrm{p}<0.05$.

quently among RA patients was determined: dyslipidemia (60.32\%), nonalcoholic fatty liver disease $(61.11 \%)$, chronic cholecystitis $(36.51 \%)$, cholesterosis of the gallbladder $(30.16 \%)$, hypertension $(37.30 \%)$, autoimmune thyroiditis $(27.77 \%)$, spinal osteoarthritis (33.33\%)

Results of the carotid ultrasonography and assessment of atherosclerosis surrogate markers (IMT, AP) showed higher severity of atherosclerotic process in patients with RA compared to controls; the most important risk factors for increasing IMT and atherosclerotic plaques in carotid arteries were dyslipidemia, autoimmune thyroiditis with hypothyroidism and nonalcoholic fatty liver disease.

Conclusions: Patients with RA have a higher frequency of comorbid conditions and diseases than controls without RA; some of comorbidities have significant influence on atherogenesis; RA patients require a multidisciplinary and holistic approach for effective management of their health related problems.

References:

[1] Characteristics of comorbid stennov u hvorih on rheumatoid arthritis. Characteristics of comorbid conditions in patients with rheumatoid arthritis. Family Medicine 2015;3(59):219-222.

Disclosure of Interest: None declared

DOI: 10.1136/annrheumdis-2017-eular.3027

\section{AB0340 CLINICAL EFFICACY OF STATINS IN PATIENTS WITH RHEUMATOID ARTHRITIS}

L. Mikulets, T. Ilashchuk. Department of Propedeutics of Internal Diseases, Higher State Educational Establishment of Ukraine "Bukovinian State Medical University", Chernivtsi, Ukraine

Background: Cardiovascular disease (CVD) is a major cause of mortality in patients with rheumatoid arthritis (RA). In the literature there are conflicting data on the use of statins in patients with RA, indicating a lack of attention to the issue of prevention of CVD in this category of patients.

Objectives: The aim of the study was to improve the efficiency of the treatment of rheumatoid arthritis by including to the basic treatment rosuvastatin.

Methods: The study included 43 patients with RA. A survey conducted by the protocol patients (DAS28 index, visual analog scale (VAS), morning stiffness). The study of lipid metabolism included: determining the level of total cholesterol (total cholesterol), HDL cholesterol (HDL) and low density (LDL), atherogenic index (AI), triglycerides (TG). Total cardiovascular risk assessment was performed using a table SCORE. Surveyed patients divided into groups: primary $(n=20)$ (basic therapy and rosuvastatin, $10 \mathrm{mg} 1$ time per day) and comparison $(n=23)$ (basic therapy that included methotrexate, non-steroidal anti-inflammatory drugs, glucocorticoids in medium therapeutic doses)

Results: As a result of the treatment found that patients with a primary and group comparison, there was a positive dynamics of clinical indicators of inflammatory activity (DAS28, VAS, morning stiffness). In the study group experienced a significant decrease $(p<0.05)$ at the same time as in the comparison group had a tendency to decrease. Noted a reduction parameters: CRP $\left(\Delta_{1} 37 \%\right.$ main group and the comparison group $\Delta_{2} 21 \%$ ), ESR ( $\Delta_{1} 39 \%$ and $\Delta_{2} 26 \%$ respectively). Also noted the changes in the lipid profile. Significantly decreased in the study group performance total cholesterol $\left(\Delta_{1} 31 \%\right.$ versus $\left.\Delta_{2} 15 \%\right)$, LDL cholesterol $\left(\Delta_{1} 19 \%\right.$ against $\left.\Delta_{2} 8 \%\right)$ and $\mathrm{Al}\left(\Delta_{1} 29 \%\right.$ and $\Delta_{2} 16 \%$ respectively).

Conclusions: Inclusion in the complex therapy of patients with RA statins contributes to a significant reduction in total cholesterol, LDL cholesterol, and positively affects the activity of the process, reducing the levels of acute phase proteins. Additional indications for the purpose of statins have high activity process and late onset. The use of statins in RA, given their lipid-lowering and anti-inflammatory effects, may be an effective means for the successful prevention of cardiovascular complications

Disclosure of Interest: None declared

DOI: 10.1136/annrheumdis-2017-eular.5983 